\title{
Study on the Reform of Assessment Mode for the Undergraduate Course of Law
}

\author{
A Case Study on the Reform of Course Assessment Mode of Branch of Civil Law*
}

\author{
Teng $\mathrm{Hu}$ \\ School of Public Affairs and Administration \\ University of Electronic Science and Technology of China \\ Chengdu, China
}

\author{
Huafeng Lu \\ School of Public Affairs and Administration \\ University of Electronic Science and Technology of China \\ Chengdu, China
}

\begin{abstract}
At present, the examination methods in the undergraduate education of law in higher education in our country are not paid attention to, which makes our examination way out of line with the practice, the examination method is rigid, the examination is not standardized and so on, which may affect the enthusiasm of the students, the fairness of the assessment results and the comprehensiveness of the evaluation of the students' curriculum. In view of this, the author's research group has carried on the examination method reform exploration in the undergraduate law education process with the "Civil law division theory" curriculum as the pilot, hoped through the curriculum appraisal way reform, which promotes students' subjective initiative in learning, strengthens the effectiveness of curriculum education, and realizes the fairness of the results of process assessment and final examination.
\end{abstract}

Keywords-law; undergraduate education; assessment method; Branch of Civil Law

\section{INTRODUCTION}

For the undergraduate education of law, the examination of curriculum is undoubtedly an important link. First, it is helpful for course teachers to test and feedback on students' learning effect, and the other is also an important index for students to evaluate their own learning performance and students' learning performance. Especially in the credit system today, the results of the course assessment not only determine whether the students can obtain a successful graduation, It is also an important reference index for whether they can obtain scholarships and obtain academic awards such as postgraduate qualifications. Therefore, the question of curriculum assessment is not a "important is only a process rather than a result" can be passed, but should arouse the attention of our legal educators However, it is precisely this important appraisal mechanism that is seriously ignored in reality. In our teaching practice, there are two kinds of traditional examination methods: one is examination paper, the other is paper inspection. Both methods should be said to have their advantages and disadvantages, but cannot be separated from the test to determine a lifetime, emphasis on the results of light

*This paper is a teaching reform project of University of Electronic Science and technology of China - the stage achievement of the inquiry case teaching Mode Reform under the information technology environment. process of the stereotype.

However, in reality, due to the long-term neglect of the improvement of undergraduate education assessment methods, the assessment methods of undergraduate law education have begun to highlight a large number of problems.

\section{The MAIN PROBlems EXISTING IN THE CURRENT} ASSESSMENT METHODS OF UNDERGRADUATE LAW COURSES IN UNIVERSITIES

\section{A. Inadequate Response to Judicial Examinations}

Judicial examination is undoubtedly the most important and influential examination in the field of contemporary Chinese law. Most undergraduate students trained in colleges and universities are faced with the screening of judicial examinations. Therefore, the implementation of judicial examination system is helpful to define the training goal of law education, to promote the reform of teaching content, teaching method and teaching management system, and to improve the disconnection between law education and legal vocational education. It will bring good opportunities for the development of law education. ${ }^{[1]}$ However, an indisputable fact is that the judicial examination has formed a strong impact on the law education in colleges and universities. In view of the difficulty of preparing for the examination, many students, especially the local college students, prepare for the judicial examination in advance. Many students begin to take special training in freshman year. In other words, the main knowledge and skills of the students in the judicial examination come not from their own universities, but from specialized training institutions, such as Wanguo, Zhonghe, New Oriental and so on specialized in dealing with the judicial examination. Although many scholars hold different views on the fact that law education in colleges and universities caters to the judicial examination, they think that legal education blindly caters to the current judicial examination, and even regards the passing rate of the judicial examination as an indicator of the success of legal education, which is bound to form a practical educational mode of doctrine, this kind of education will develop into examination-oriented education, and the quality of legal education will decline with it. ${ }^{[2]}$ However, it is undeniable that some famous schools that attach importance to theoretical literacy education have encountered an awkward situation in 
which the rate of passing the judicial examination is not as good as that of ordinary colleges or even some schools of two or three. However, the qualification for judicial practice is the basic qualification for every professional engaged in legal profession. If he fails to pass the judicial examination, the graduate of law may become a difficult position that he can't engage in the profession of law, although he has full of theories of law. Therefore, in today's China, the undergraduate law education in Colleges and universities must respond to the judicial examination and act together. In this kind of linkage, we think that it is necessary and feasible to introduce certain contents and forms of examination to the students of law science.

\section{B. The Single Assessment Method Is Not Enough to Evaluate the Students' Academic Level Comprehensively and Objectively}

At present, in the undergraduate law education in our colleges and universities, the way to assess the academic performance of law major students is mainly to examine the examination papers, and from what the author has learned from teaching for more than 20 years, Almost most of the tests are done by closing (or opening) final papers, which also form the main source of students' grades. It has to be said that this single way of assessment is only from theory to theory, from the point of knowledge to the level of knowledge things, cannot make an objective and comprehensive evaluation of the learning effect of students. The specialty of law is one with strong practicality. It is difficult to judge the students' application ability, practice ability, autonomous learning ability and innovation ability by a single written examination, and it is also easy to lead to the weakness of students' practical ability. At the same time, most colleges and universities in our country adopt the examination method of "one test for life", that is, through the final examination results, as the main basis to evaluate the students' mastery of the course. Obviously, "one test for life" cannot fully reflect the real situation of students' learning, it is unfair and objective. Students' mastery of what they have learned is complicated and gradual, so it is unscientific and incomplete to draw a conclusion based on the results of a final exam or a half-term exam. Only through a variety of ways to carry on the multi-angle and omnidirectional examination to the student's study condition, can make the correct appraisal to the student's academic achievement more scientifically. ${ }^{[3]}$

\section{The Formality of Examination and Assessment Is Too Rigid to Meet the Needs of Modern Teaching}

Benjamin Bloom, an American educator and psychologist, believes that the cognitive goal of education is divided into six levels: knowledge, understanding, application, analysis, synthesis and evaluation, which form a ladder from low to high. ${ }^{[4]}$ From the general situation at present, there are several main types of examination questions in law major: multiple choice questions, judgment questions, noun explanation questions, simple answer questions, discussion questions and case analysis questions. Among these types, in addition to the subjective questions such as discussion questions and case analysis questions, which have a more flexible and comprehensive understanding, application, analysis, synthesis and evaluation, other question types such as multiple choice questions, judgment questions, noun explanation questions, etc. are more limited to the lower education level of knowledge and understanding. Especially for the objective type, this phenomenon is more prominent and obvious. For the social science, which is mainly focused on application, the lack of high-level educational cognition in the present law education should be paid great attention to. On the one hand, this low level education method cannot adapt to the information update speed in the information age, resulting in the limited amount of knowledge transfer. On the other hand, modern students of legal science have diversified the ways of acquiring knowledge, and the rigid examination methods can not only not really stimulate their interest in learning, but may even cause antipathy. In addition, the emergence of new teaching modes such as turnover classroom and MOOC makes the simple examination in law education become incompatible with the times.

\section{Nonstandard Examination Methods Such as Paper Examination and Other Examination Forms Are Irregular}

At present, although most of the courses in undergraduate law education in colleges and universities are conducted by examination, there are still quite a number of teachers who use non-examination methods in their courses, especially in some elective courses or public courses, which is a common phenomenon that the examination method is based on the conclusion of the thesis. Therefore, many colleges and universities law course non-examination also mainly adopts the paper form to carry on the examination. The reasons for taking papers as an examination method can be roughly summed up as follows: first, most of the training programs of law majors in colleges and universities are vague about the examination form, and there is no specific detailed standard for the examination form after that. The absence of the standard makes this kind of "operable" examination method to be popular. Second, teachers lack a correct understanding and understanding of the status and role of curriculum assessment in teaching, and there is no incentive mechanism for teachers to try new assessment methods in the teaching link. As a result, teachers lack of motivation and initiative in the exploration of new curriculum assessment methods, so it is natural for teachers to choose the thesis as the final course assessment because of inertia thinking. Of course, the advantage of this way is that it can train the students' comprehensive ability, especially the ability of language expression, logical thinking and research, especially for the students who are interested in the academic path in the future. However, due to the subjective nature of the examination form of the paper and the lack of practical operational norms, the effect of the examination and even the way of the examination itself are also worthy of questioning.

In short, from the current examination of undergraduate law education, due to the excessive emphasis on students' memory ability, rather than analysis, reasoning ability, more attention is paid to whether the final conclusion is correct or not, rather than whether the process of inference is rigorous and thorough. The situation of this kind of examination obviously conflicts with the characteristics of the practice of law specialty. Therefore, it is necessary to explore the reform of undergraduate law teaching assessment under the concept of 
modern education, and the author's research group has carried out related research based on this purpose. In the following, we will answer this proposition based on the relevant teaching reform in the course of Civil Law.

\section{THOUGHTS ON THE REFORM OF THE TARGET COURSE SELECTION IN THE EXAMINATION MODE}

The traditional curriculum assessment methods have insufficient and shortcomings mentioned above. However, it is undeniable that both examinations and check have their realistic rationality and significance, and some of the law courses are not unnecessarily the most appropriate, such as the history of legal system, ideological history and other theoretical, memorable courses, the traditional assessment method is still of considerable value. According to the investigation, at present, the majority of the law departments in colleges and universities mainly assess students' scores in two major parts: first, the results of the period examination, that is, the results of the final examination papers, which generally account for $70 \%$ or $60 \%$; and the second, the grades in peacetime, including homework, practical teaching and attendance and so on, generally accounting for $30 \%$ or $40 \%$. ${ }^{[5]}$ Therefore, we should not be free to choose professional courses, but should be targeted. After screening, we decided to choose the course of "Civil law (Branch)" (hereinafter referred to as "Branch of Civil Law ") to carry on the teaching reform pilot of the examination way. The main reasons are as follows:

\section{A. The Course Has Many Contents and Covers a Wide Range of Areas}

As Mr. Liang Huixing said: " When I was in class, I thought the contents of civil law were too much " Not to mention the division between civil law and commercial law, the rules in the areas of companies, bills, maritime merchants, insurance and so on have been separated as commercial laws. The formal civil law disciplines also include general principles, real rights, creditor's rights, relatives, inheritance, etc. The creditor's rights are also divided into the general principle of creditor's rights and the subdivision of creditor's rights, the creditor's rights principle further distinguishes between contract and infringement." ${ }^{[6]}$ Due to the existence of a large amount of complicated knowledge points and it is not effective for students to use forced memory only, the traditional assessment method not only results in the low performance of the students, And more highlights the above mentioned the shortcomings of the traditional way of assessment. Therefore, we think that it is feasible and necessary to introduce new assessment methods and mechanisms, to emphasize the examination of various models of curriculum, to emphasize understanding and deep study, to arouse students' interest in the course of civil law division, and to strengthen the learning effect.

\section{B. The Course Has Strong Practicality and High Requirement for Case Teaching}

The course of civil law division theory is the study of specific civil law content, such as real right, creditor's right, contract and so on, which is more close to the practice of law than the general part, and emphasizes the deep mastery and skillful application of the content of the law. Therefore, the teaching of this course will of course have a large number of case teaching content, and the case of the interpretation and understanding of the depth of higher requirements. In this process, practice and case-teaching will obviously occupy a large proportion in classroom teaching. However, if we adopt the traditional examination method, whether it is a closed examination or a paper inspection, there will undoubtedly be a problem that the above two characteristics are not clearly reflected. Students are also more focused on the test and tend to ignore what they really need to learn and master. At the same time, the strong practicality and a large number of cases teaching also provide the opportunity and the suitable experimental object for the new examination way experiment.

\section{The Course Has the Early Accumulation of Knowledge and Reserves, Which Provides the Basis for the \\ Implementation of New Assessment Methods and Teaching Methods}

With the development and progress of educational theory, a large number of new forms of teaching methods and means are constantly emerging, which makes the undergraduate education of law in modern colleges or universities to respond actively or passively. Among them, flipping classroom is more common in Chinese colleges and universities. "flipping classroom is also called subversion to classroom, through the reverse arrangement of knowledge imparting and knowledge internalization, the role of teachers and students in traditional teaching has been changed, and the use of classroom time has been replanned, thus the innovation of traditional teaching mode has been realized." ${ }^{[7]}$ However, the author believes that the application of this model must have certain restrictions and operating basis, which is the most important is that students must have a certain amount of knowledge and theoretical knowledge before the use of this model, in order to make the inverted classroom have something to say, each has its own gains. Otherwise, it is the form of "somersault" and become meaningless. Therefore, for the course of civil law division theory, in the course system of law course, the students have studied the general theory of civil law for one semester in advance, and the students are concerned about the related concepts and the basic system, spirit of civil law and principle has better knowledge retention and a certain degree of desire for knowledge, which has the natural favorable conditions for the development of the flipping classroom. At the same time, the flipping classroom also corresponds to the corresponding assessment standard and content, which undoubtedly provides sufficient conditions for us to carry out the reform of the law subject examination mode based on this course.

\section{THE SCHEME DESIGN OF THE REFORM OF EXAMINATION MODE}

For the above reasons, our research group has chosen the civil law divided theory as the experimental object for the reform of undergraduate legal education assessment mode, and has made a relatively complete design of the whole reform program. The specific schemes are as follows:

\section{A. The Overall Guiding Ideology of Reform}

Traditional teaching is mainly classroom teaching, students are relatively passive, classroom participation enthusiasm is not high. This project adopts the method of case teaching, flipping class and teacher teaching, and makes every effort to 
mobilize students' active learning: full preparation before class, active participation in class, development and sublimation after class. At the same time, the classroom exercises, after-class homework and teaching practice are brought into the process management, combined with the construction of question bank, the application of information technology and the reform of the examination method, in order to explore and construct a modern teaching model different from the traditional teaching mode.

\section{B. Expected Objectives of Reform}

- Through case teaching, we can guide students to establish the ability of inductive thinking from concrete to general, deductive thinking from general to concrete, and the ability to analyze and solve problems by using the theory learned.

- By "flipping the classroom", students can learn to learn independently, form the habit of critical thinking and creative thinking, acquire the ability to integrate and apply the knowledge of the subject, and in data collection, collation, content output to train students "listening, speaking, reading, writing" the new four skills.

- Through the process management of pre-study, classroom participation, homework and practice after class, the students can be fully motivated to study consciously and actively, and the model of "one test for life" should be avoided in the past performance assessment.

\section{The Design Thought of the New Examination Mode after the Reform}

1) Emphasizing the diversification of examination methods and improving the comprehensiveness of examination: In view of the traditional examination method is "One test for life" and monotony of assessment methods, this design scheme intentionally strengthens the diversity and richness of the assessment methods. From the time line, the new assessment method pays attention to the full-time learning assessment from pre-class, in-class to after-class, and tries to change the limitations of "one exam determines one's life". From the space line, the new assessment method not only requires students to complete the classroom and examination room examination, but also to take the course content of learning to the home and dormitory. In terms of assessment methods, it not only retains the traditional classroom test, closed-book examination and other ways, but also introduces more diverse and comprehensive assessment methods.

2) Dividing the examination into different stages and paying attention to the comprehensiveness of the examination: The teaching contents and knowledge points of civil law theory course are very rich, case and classroom discussion almost run through the course all the time. Therefore, if there is only one final exam, the coverage of the content alone has great limitations. Take universities in the United States, for example, whose courses are more frequently tested throughout the semester: they have not only routine mid-term exams, but also class tests. The total number of exams and tests per course in just four months of a semester is less than two, more than five or six. ${ }^{[8]}$ Stones from other hills can be used to attack jade. This kind of multi-stage and multifrequency assessment in American universities is undoubtedly beneficial to the overall assessment of students' abilities and the maintenance of curriculum tension. In view of this, in the design of our new plan, in addition to the traditional mid-term and final exams, we have added additional methods and methods, such as pre-class prep tests, peacetime case analysis tests, classroom random spot checks and so on, a comprehensive evaluation of the whole learning process of students is carried out with different weights.

3) Guiding the classroom performance into the examination standard, improving the student participation and the feedback degree of the course examination: Students' classroom performance mainly refers to the degree of students' concentration and interaction with teachers in the process of classroom teaching. Classroom performance should be said to be the most intuitive indicator reflecting the teaching effect, and is also the most direct way for teachers to receive feedback from students, especially in advocating flipped classroom. It is necessary to introduce classroom performance into assessment mechanism to adjust students' initiative and interactivity. Therefore, when we design a new civil law theory assessment weight distribution, we will increase the scores of students' initiative, enthusiasm and accuracy in participating in flipped classes and interacting with teachers, So as to stimulate students' participation in classroom teaching and reflect the feedback of curriculum assessment.

4) Strengthening the design of test questions, echoing the judicial examination: The importance of judicial examination in China has been mentioned before, and civil law theory plays an important role in the whole judicial examination. In the 2017 judicial examination, the civil law accounted for 90 points in the total score, with the highest score of a single subject juxtaposed with the criminal law, this situation can almost be said to be the norm over the years. In these 90 points, almost all of the scores will involve the content and knowledge of the theory of civil law. Therefore, whether in theory or in reality, the course does not echo the judicial examination and knowledge grant, no doubt, it is out of practice and closed behind doors. For this reason, in designing the evaluation reform scheme, whether in peacetime, in the mid-term or in all kinds of final examination, we all try our best to join the real questions of the judicial examination in the past years, with a view to achieving the practical use of learning.

\section{Concrete Design of Examination Mode}

Combined with the above design ideas, we have drawn up a combination of various assessment methods. The details are as follows: 
- In order to realize the purpose of stage assessment and to preheat the knowledge in the early stage, the summer vacation before school begins requires the students to prepare the first three chapters of the teaching content. At the same time, the combination of information technology, embedded rain classroom, the establishment of teaching classes. Advance release of preview courseware requires students to preview through mobile phone terminal, issue exercises and reference answers, and can achieve interactive communication with students through rain classes. Through rain class, students can know whether to preview the teaching content and whether the preparation is completed. And in the first class in the beginning of the preview test, the test in the whole curriculum assessment accounted for $5 \%$;

- As a variety of assessment methods, but also to promote the students to learn the comprehensive use and integration of knowledge, so as to increase the intensity of ordinary written work requirements. During the whole course of civil law division, teachers will use case teaching method in a large amount, lead cases, study cases in the course and test what they have learned in class after class. Assign at least three assignments in writing. The proportion of this part in the whole course examination is $10 \%$.

- When the course is almost halfway through, students will be asked to take a midterm test. Adopting the method of closed-book quiz in class, the author chooses the relevant questions of civil law theory in Volumes 1, 2 and 3 of the true questions of the judicial examination calendar year, and the appropriate number of questions is within 50 . The examination score of this part is $15 \%$.

- Normally the classroom performance is also tested, such as answering questions, participating in classroom seminars and speeches, by the discretion of teachers, scores accounted for $10 \%$;

- Part of the teaching content is introduced into the flipping classroom. For example, the personal right in the teaching content is compiled in the form of flipping classroom, the teacher issues the guiding learning plan, and lists a number of questions, which require the students to explain in the classroom after self-study, and to combine the students' questions with each other and the teacher's comments. According to the completion of the courseware made by the students, the classroom explanation for comprehensive evaluation, the proportion of score is $10 \%$.

- A final exam. The form of final examination is to choose the way of combining the real questions of the judicial examination with the theoretical investigation. The form of the examination is closed paper, the score of the paper is 100 points, and the proportion of score is $50 \%$.

\section{CONCLUSION}

The pilot of this assessment method started in the civil law divided theory of law sophomore in September 2017, after a semester of pilot and exploration, we found that this way of assessment is feasible. Through this method of comprehensive assessment, the whole process of students' learning, the supervision and feedback of the whole period of time are really strengthened, so that the fairness, comprehensiveness and scientificalness of the assessment results are strengthened to a certain extent. At the same time, the reform of this kind of examination method, on the one hand, urges teachers to try various teaching methods, to use various teaching means, and also to be closer to the practical application of law; On the other hand, it promotes the interaction and communication between teachers and students, and is more conducive to the students' deep understanding of knowledge points and difficult feedback. In short, through this pilot reform, we found that civil law teachers should bear more responsibilities in training students' legal wisdom and skills, and should do their utmost to cultivate students' legal thinking ability with the "law of discovery" as the core in the classroom. Let the teaching of civil law advance towards the true purpose of law education.

\section{REFERENCES}

[1] See Huang Wei: Review and Prospect of China's Judicial examination system, Published in Xu Xin : "justice" (Third Series), Xiamen University press 2008 Edition, p 283.

[2] See Zhang Jianwei : "The impact of judicial examination on law education: observation and reflection", Published in "The people's court newspaper", September 9, 2010, $7^{\text {th }}$ edition.

[3] See Cui Dong, Hu Min, Xie Feifei : A preliminary study on the Reform of the examination methods for the students' academic achievements of Law majors , Published in "Educational Exploration", The first issue, 2014.

[4] Quoted from Zhu Jing: "On the Reform of the examination method of the course of Law Specialty", Published in "Heihe Journal", The first issue, 2013

[5] See Yu Fudong, Peng Xiang: "Exploration on the Reform of the Evaluation Mechanism of Law students' Achievement", Published in "An overview of history and history (Theory)", January 2009.

[6] Liang Huixing : On the characteristics and Learning methods of Civil Law, China Law Network, December 19, 2016 http://www.360doc.com/content/16/1219/15/29807794_616017598.sht $\mathrm{ml}$

[7] Zhang Jinlei,, Wang Ying, Zhang Baohui: A study on the mode of flipping classroom teaching, Published in the Journal of distance education, The fourth issue, 2012.

[8] See Cui Dong, Hu Min, Xie Feifei: A preliminary study on the Reform of the examination methods for the students' academic achievements of Law majors, Published in "Educational Exploration", The first issue, 2014. 